Published in final edited form as:

J Am Chem Soc. 2007 October 31; 129(43): 13118-13126. doi:10.1021/ja073905m.

\title{
Spectroscopic and Kinetic Studies of Perturbed Trinuclear Copper Clusters: The Role of Protons in Reductive Cleavage of the O-O Bond in the Multicopper Oxidase Fet3p
}

\author{
Anthony J. Augustine ${ }^{\dagger}$, Liliana Quintanar ${ }^{\dagger}$, Christopher S. Stoj§, Daniel J. Kosman§, and \\ Edward I. Solomon ${ }^{\dagger}$ \\ $\dagger$ Department of Chemistry, Stanford University, Stanford, California 94305 \\ $\S$ Department of Biochemistry, School of Medicine and Biomedical Sciences, State University of New York, \\ Buffalo, New York 14214
}

\begin{abstract}
The multicopper oxidase Fet3p couples four $1 \mathrm{e}^{-}$oxidations of substrate to the $4 \mathrm{e}^{-}$reduction of $\mathrm{O}_{2}$ to $\mathrm{H}_{2} \mathrm{O}$. Fet3p uses four $\mathrm{Cu}$ atoms to accomplish this reaction: the type 1, type 2, and coupled binuclear type 3 sites. The type 2 and type 3 sites together form a trinuclear $\mathrm{Cu}$ cluster (TNC) which is the site of $\mathrm{O}_{2}$ reduction. This study focuses on mutants of two residues, E487 and D94, which lie in the second coordination sphere of the TNC and defines the role that each plays in the structural integrity of the TNC, its reactivity with $\mathrm{O}_{2}$, and in the directional movement of protons during reductive cleavage of the O-O bond. The E487D, E487A, and D94E mutants have been studied in the holo and type 1 depleted (T1D) forms. Residue E487, located near the T3 center, is found to be responsible for donation of a proton during the reductive cleavage of the $\mathrm{O}-\mathrm{O}$ bond in the peroxide intermediate and an inverse kinetic solvent isotope effect, which indicates that this proton is already transferred when the O-O bond is cleaved. Residue D94, near the T2 site, plays a key role in the reaction of the reduced TNC with $\mathrm{O}_{2}$, and drives electron transfer from the $\mathrm{T} 2 \mathrm{Cu}$ to cleave the $\mathrm{O}-\mathrm{O}$ bond by deprotonating the $\mathrm{T} 2 \mathrm{Cu}$ water ligand. A mechanism is developed where these second sphere residues participate in the proton assisted reductive cleavage of the O-O bond at the TNC.
\end{abstract}

\section{Introduction}

The multicopper oxidase (MCO) family of enzymes couples the oxidation of four equivalents of a one-electron donor to the four electron reduction of dioxygen to water. ${ }^{1}$ These enzymes can be separated into two types by substrate specificity. The first group catalyzes the outer sphere oxidation of small organic substrates: the plant ${ }^{2}$ and fungal laccases ${ }^{3}$, ascorbate oxidase $^{4}, \operatorname{CotA}^{5}$, and phenoxazinone synthase ${ }^{6}$. The second group oxidizes metal ions at highly specific metal ion binding sites ${ }^{7-9}$ : Fet $3 \mathrm{p}^{10}$, ceruloplasmin ${ }^{11}, \mathrm{CueO}^{12}$, and $\mathrm{MngX}^{13}$. All MCOs must have at least one type 1 (T1) or blue $\mathrm{Cu}$ site, a type 2 (T2) or normal $\mathrm{Cu}$ site, and a type 3 (T3) or coupled binuclear copper site, where two $\mathrm{Cu}$ (II) atoms are antiferromagnetically (AF) coupled by a bridging hydroxide ligand (Figure 1). ${ }^{1}$ Spectroscopic evidence has shown that the T2 and T3 Cu sites are located close to one another (within 4 $\AA$ ) forming a trinuclear $\mathrm{Cu}$ cluster ${ }^{14,15}$ which has been confirmed by various crystallographic studies. ${ }^{16,17}$ This is the site of $\mathrm{O}_{2}$ reduction. ${ }^{18}$

Electrons from the reducing substrate are supplied to the MCOs through the $\mathrm{T} 1 \mathrm{Cu}$ site and then transferred over $13 \AA$ via a highly conserved Cys-His electron transfer pathway to the trinuclear cluster (TNC) for oxygen reduction. The fully reduced enzyme reduces dioxygen to water in two, 2 electron steps. ${ }^{19}$ When the fully reduced holo-form of the enzyme reacts with $\mathrm{O}_{2}$ it forms the native intermediate (NI) which then decays to the resting oxidized enzyme. 
20,21 A variety of spectroscopic methods have been used to characterize NI; these have shown that the enzyme is in fact, fully oxidized. Therefore, $\mathrm{O}_{2}$ has been fully reduced but remains bound to the TNC as $\mu_{3}$-oxo and $\mu_{2}$-hydroxo bridges. ${ }^{22,23}$ The decay of NI to the resting oxidized state involves loss of the $\mu_{3}$-oxo bridge ${ }^{24}$ and is slow relative to the rate of turnover in the MCO reaction; therefore, this decay process cannot be catalytically relevant.

Consequently, NI, and not resting, is the fully oxidized form of the enzyme in the catalytic cycle. $^{1}$

Type $1 \mathrm{Cu}$ depleted forms of the MCOs, where the $\mathrm{T} 1$ is replaced by a spectroscopic and redox innocent $\mathrm{Hg}^{2+}$ ion $(\mathrm{T} 1 \mathrm{Hg})$ in the case of laccase ${ }^{25}$, or by mutating the Cys residue at the $\mathrm{T} 1$ site to a Ser residue (T1D) in Fet3p 26,27 , have also been studied. In these derivatives, when the enzyme is fully reduced it only has three electrons available to reduce dioxygen. This leads to the formation of a peroxide intermediate (PI) in which one $\mathrm{Cu}$ at the TNC stays reduced and the other two have been oxidized, transferring two electrons to $\mathrm{O}_{2} .{ }^{28} \mathrm{PI}$ forms very rapidly and is kinetically competent to be a precursor to NI. ${ }^{29}$ Spectroscopic and computational studies have shown that the peroxide in PI is bound internally and bridges the T2 and T3 Cu sites. $27,28,30,31$ PI then decays with oxidation of the remaining reduced $\mathrm{Cu}$ site to the resting oxidized form through an NI species as seen by magnetic circular dichroism spectroscopy. When a redox active $\mathrm{T} 1$ is lacking, this decay is very slow, due to the large barrier associated with the one electron reductive cleavage of the peroxide $\mathrm{O}-\mathrm{O}$ bond, as opposed to the low barrier associated with the thermodynamically favorable two electron reductive $\mathrm{O}-\mathrm{O}$ bond cleavage in the holo form of the enzyme. ${ }^{32}$

Examination of the crystal structure of Fet3p shows that there are two second sphere carboxylate residues, D94 and E487 (Figure 1), within $\sim 8 \AA$ of the TNC that are conserved in all archived MCO proteins $(n>900)$. These residues have been thought to possibly play a role in the structural integrity of the TNC, as well the $\mathrm{pH}$ dependence of the spectroscopy of the resting T2 Cu site ${ }^{33}$ and the decay of PI to NI, which is enhanced by increasing proton concentration and shows an inverse kinetic solvent isotope effect (KSIE) at low pH. ${ }^{33,34}$. In the case of the $\mathrm{pH}$ effect on the resting $\mathrm{T} 2 \mathrm{Cu}$ site, ESEEM spectroscopy showed that this did not result from protonation of the hydroxide ligand on the $\mathrm{T} 2 \mathrm{Cu}$, as it remains deprotonated even at $\mathrm{pH}<5$. 33 This supported the possibility that residue D94, located near the $\mathrm{T} 2 \mathrm{Cu}$, is responsible. In another study, we investigated the role of D94 and found through its mutation that it affects both the decay of PI and the pH effect on the resting enzyme. In addition, in the D94A mutant the reduced TNC does not react with oxygen. ${ }^{34}$ However, the contribution of residue $\mathrm{E} 487$ to these $\mathrm{pH}$ effects and $\mathrm{O}_{2}$ reactivity has not been addressed.

This study extends our previous work to D and A mutants of E487 and allows definition of the individual contributions of these residues to reactivity. A variety of spectroscopic methods are employed to evaluate the impact of these mutations on the structural integrity of the TNC, and kinetic studies are presented on the decay of PI to determine the role which protons play in the reductive cleavage of the $\mathrm{O}-\mathrm{O}$ bond. The $\mathrm{pH}$ dependence of $\mathrm{PI}$ decay is now uncoupled from the $\mathrm{pH}$ effect on the resting $\mathrm{T} 2 \mathrm{Cu}$. Residue $\mathrm{E} 487$ is shown to be directly responsible for the $\mathrm{pH}$ dependence and KSIE associated with the decay of PI. Alternately, residue D94 is found to be required for the $\mathrm{O}_{2}$ reaction of the TNC and facilitates $\mathrm{O}-\mathrm{O}$ bond cleavage through the deprotonation of the water ligand on the T2 $\mathrm{Cu}$ of PI in the decay to NI.

\section{Experimental Procedures}

Water was purified to a resistivity of $15-17 \Omega \mathrm{M} \mathrm{cm}^{-1}$ using a Barnstead Nanopure deionizing system. All chemicals were of reagent grade and used without further purification. Mutant FET3 alleles were constructed in pDY148 by site-directed mutagenesis using the QuikChange kit from Stratagene. Complementary primers were used in PCR amplification of the vector to 
generate E487D, E487A, and D94E mutants. The following double mutants were then generated in two sequential rounds of mutagenesis: T1D/E487D, T1D/E487A, and T1D/D94E. The FET3 mutant sequences were confirmed by automated fluorescence sequencing on an ABI PRISM 377 instrument. The vectors expressing the mutant proteins were transformed into yeast strain M2* for soluble protein expression. Then WT, T1D, E487D, T1D/E487D, E487A, T1D/E487A, D94E, and T1D/D94E proteins were expressed, isolated, and purified as previously described. 35,36 The Bradford dye-binding assay was used to determine protein concentrations ${ }^{37}$ and copper content was determined spectrophotometrically with 2,2-

biquinoline ${ }^{38}$. Spin quantitation of EPR spectra used a $1.0 \mathrm{mM} \mathrm{CuSO}_{4} \cdot 5 \mathrm{H}_{2} \mathrm{O}, 2 \mathrm{mM} \mathrm{HCl}$ and $2 \mathrm{M} \mathrm{NaClO}_{4}$ standard solution to determine the concentration of paramagnetic copper. 39

All steady-state kinetic studies were carried out based on oxygen consumption using an Oxygraph (Hansatech, www.hansatech-instruments.co.uk). The $\mathrm{O}_{2}$ uptake rates were evaluated using the OXYG32 software provided by Hansatech. All initial velocity, $v$, versus [S] data were analyzed by direct fitting to the Michaelis-Menten equation using Prism 4 . These studies all used ferrous ammonium sulfate as the substrate. Stock solutions were freshly prepared in nitrogen-purged $100 \mathrm{mM}$ MES at $\mathrm{pH} 6.0$ and transfers from these stock solutions were carried out using gastight syringes. All reactions were carried out in air-saturated 100 $\mathrm{mM}$ MES at $\mathrm{pH}$ 6.0.

UV-Visible absorption spectra were obtained using either an Agilent 8453 or a HewlettPackard HP8452A diode array spectrophotometer. EPR spectra were measured with a Bruker EMX spectrometer, ER 041 XG microwave bridge, and ER 4102ST cavity. A liquid nitrogen finger dewar was used to maintain a temperature of $77 \mathrm{~K}$ for all X-band samples. Q-band measurements were made at $77 \mathrm{~K}$ using an ER $051 \mathrm{QR}$ microwave bridge, ER 5106QT resonator, and an Oxford continuous flow CF935 cryostat. All EPR simulations were done using XSophe (Bruker). UV-visible circular dichroism (CD), at room temperature, and magnetic circular dichroism (MCD), at $5 \mathrm{~K}$, were measured with a Jasco J-810-150S spectrapolarimeter coupled with an S-20 photomultiplier tube and an Oxford SM4000-8T magnet. In the near-IR region, CD and MCD spectra were measured with either a Jasco 200D or J-730 spectrapolarimeter and a liquid nitrogen cooled InSb detector with either an Oxford SM4000-7T or SM40008T magnet. CD spectra were measured in a $0.5 \mathrm{~cm}$ quartz cuvette. MCD spectra were measured using cells which were fitted with two quartz disks and a 3-mm rubber spacer. To eliminate zero-field baseline effects in MCD, the spectra are an average of the $+7 \mathrm{~T}$ and $-7 \mathrm{~T}$ scans, $[7-(-7)] / 2 \mathrm{~T}$. Gaussian fitting of the absorption, $\mathrm{CD}$, and MCD data was done using PeakFit 4.0 (Jandel).

For spectroscopic characterization, samples were made in either $100 \mathrm{mM}$ sodium phosphate buffer (for pDs between 6 and 8) or $100 \mathrm{mM} \mathrm{MES} \mathrm{buffer} \mathrm{(for} \mathrm{pDs} \mathrm{between} 4.7$ and 6). To make an optical quality glass when frozen for MCD, a $50 \%$ (v/v) buffer/glycerol-d3 mixture was used yielding final protein concentrations from $0.3-0.8 \mathrm{mM}$.

For PI decay studies, protein samples were prepared as previously reported. ${ }^{32,34}$ Final concentrations were $40-50 \mu \mathrm{M}$ protein and $0.5 \mathrm{mM} \mathrm{O}_{2}$. For these experiments two buffers were used: $100 \mathrm{mM}$ sodium phosphate buffer (pHs and PDs between 6 and 8.5), and $100 \mathrm{mM}$ MES buffer (pHs and pDs between 4.7 and 6). Both buffers were used at $\mathrm{pH}=6$ and no difference was found in the rate of PI decay.

\section{Results and Analysis}

\section{Characterization of holo outer sphere Fet3 mutants}

WT as well as E487D, E487A, and D94E mutants were isolated in their holo-forms. These were screened by measuring $\mathrm{Cu}$ content, absorption spectra, EPR spectra, and their spin 
quantitation. All load $\sim 4 \mathrm{Cu} /$ protein. WT, E487D, and D94E have $\sim 2$ spins/protein (T1 and T2 sites) while the E487A mutant was lower, at $1.2 \pm 0.4$ spins/protein (table 1). The absorption spectra of WT and the three mutants (figure S1A, Supporting Information) are dominated by two intense charge transfer (CT) transitions, one at $16,450 \mathrm{~cm}^{-1}(608 \mathrm{~nm})$ with $\varepsilon=5500$ $\mathrm{M}^{-1} \mathrm{~cm}^{-1}$ from the oxidized $\mathrm{T} 1 \mathrm{Cu}$ site and another around $30,300 \mathrm{~cm}^{-1}(330 \mathrm{~nm})$ with $\varepsilon=$ $5000 \mathrm{M}^{-1} \mathrm{~cm}^{-1}$ from the oxidized T3 $\mathrm{Cu}$ site. ${ }^{40,41}$ This has been assigned as a bridging $\mathrm{OH}^{-}$to $\mathrm{T} 3 \mathrm{Cu}$ (II) CT transition. The EPR spectra of the mutants were also similar to that of WT, showing T1 and T2 Cu contributions (figure S1B, Supporting Information). Turnover kinetics studies were also performed and show that all the mutants carry out multiple turnovers in the presence of oxygen and $\mathrm{Fe}^{2+}$ as substrate (table 2).

\section{Characterization of T1D outer sphere mutants}

After characterization in the holo-forms, type $1 \mathrm{Cu}$ depleted (T1D) derivatives were prepared for the above enzymes (T1D, T1D/D94E, T1D/E487D, and T1D/E487A) by introducing a C484S mutation. ${ }^{26}$ All were again screened by measuring $\mathrm{Cu}$ content, absorption and EPR spectra, and spin quantitation of their EPR spectra. As shown in table 1, each variant contained the expected $\sim 3 \mathrm{Cu}$ atoms/protein ( $1 \mathrm{Cu}$ having been eliminated by the T1D mutation) and $\sim 1$ spin/protein (T2 only). Their spectroscopy and reactivity are given below.

\section{Spectroscopic Characterization of the Resting Trinuclear Cluster}

3a. Effects of Outer sphere mutations on the T3 Cu site-Since the T3 Cu site is AF coupled, it does not contribute to the EPR and MCD spectra but does to the absorption and CD spectra. ${ }^{27,30}$ In the holo enzyme there is a contribution from the $\mathrm{T} 1 \mathrm{Cu}$, which is not found in the T1D derivative. The absorption and CD spectra of T1D, T1D/E487D, T1D/E487A, and T1D/D94E are shown in Figure 2. All of the absorption spectra are dominated by the intense $\left(\varepsilon \approx 3000 \mathrm{M}^{-1} \mathrm{~cm}^{-1}\right) \mu \mathrm{OH}^{-} \rightarrow \mathrm{T} 3 \mathrm{Cu}$ (II) $\mathrm{CT}$ transition at $30,300 \mathrm{~cm}^{-1}(330 \mathrm{~nm}) .{ }^{42}$ There is an additional weak transition present in the absorption spectrum at $\sim 700 \mathrm{~nm}$ associated with the $\mathrm{T} 3 \mathrm{Cu} \mathrm{LF}$ transitions, which are more pronounced in the $\mathrm{CD}$ spectrum (Figure $2 \mathrm{E}-\mathrm{H}$ ). The simultaneous Gaussian fit of the absorption and CD spectra requires 9 transitions (figure $\mathrm{S} 2$, Supporting Information). Based on their Kuhn Anisotropy factors (ratio of CD to absorption intensity), it has been determined that bands 1-6 are ligand field (LF) transitions of the T3 Cu's and bands 7-9 are CT transitions. ${ }^{27}$ Both of the E487 mutants show no change in the LF of the $\mathrm{T} 3 \mathrm{Cu}$ 's (compare figures $2 \mathrm{~F}$ and $2 \mathrm{G}$ to $2 \mathrm{E}$ ). The D94E mutation, however, has led to a change in the T3 LF transitions (compare bands 1-6 in Figure 2H to 2E). Three of the six LF transitions- bands 3, 4, and 6 - have been shifted more than the others in the D94E mutant which indicates that one of the T3 Cu's has been perturbed by this mutation. This correlates with D94 being H-bonded to a His ligand on only one of the T3 Cu's (Figure 1).

The intense transition at $330 \mathrm{~nm}, \mathrm{a} \mu$-hydroxide to $\mathrm{T} 3 \mathrm{Cu}$ (II) $\mathrm{CT}$ transition is resolved into two bands, 8 and 9, based on the CD spectra, indicating that the two T3 Cu's must be inequivalent, each having a distinct $\mathrm{OH}^{-} \rightarrow \mathrm{Cu}(\mathrm{II}) \mathrm{CT}$ transition. ${ }^{27,40}$ In both the E487D and E487A mutants, band 8 has not been shifted relative to WT, while band 9 has moved to higher energy (compare figures $2 \mathrm{~F}$ and $2 \mathrm{G}$ to $2 \mathrm{E}$ ). This change suggests that mutation of residue $\mathrm{E} 487$ leads to a perturbation of $\mathrm{T} 3 \mathrm{Cu}$ site. This is consistent with the crystal structure of ascorbate oxidase $^{16}$, (water molecules have not been resolved in the structure for Fet $3 \mathrm{p}^{17}$ ) where residue E487 is hydrogen bonded through an ordered water molecule to the T3 Cu hydroxide bridge (Figure 1) and this H-bond network would likely be perturbed in both mutants. In addition, from Figure 2 the D94E mutant also has an affect on the energies of the $\mathrm{OH}^{-} \rightarrow \mathrm{T} 3 \mathrm{Cu}$ (II) CT transitions despite its being located on the opposite side of the cluster. The one remaining CT transition which can be resolved at an energy $<33,000 \mathrm{~cm}^{-1}$ is band 7 which is assigned as a His $\pi \rightarrow \mathrm{Cu}$ (II) CT transition. This band is very similar in T1D and the E487 mutants, however the T1DD94E mutation has caused this band to decrease in energy and increase in negative 
intensity in the $\mathrm{CD}$ spectrum relative to the absorption spectrum (this is reflected in the increase in the C/D ratio of band 7 for T1DD94E in figure S2, Supporting Information).

3b. Effects of outer sphere mutations on the resting T2 Cu site-In all of the T1D mutants, the paramagnetic $\mathrm{T} 1$ site has been removed and the $\mathrm{T} 3 \mathrm{Cu}$ site is diamagnetic; therefore, the MCD and EPR spectra selectively probe the T2 Cu site. Both X-band $(\sim 9.4 \mathrm{GHz})$ and Q-band ( $34 \mathrm{GHz})$ EPR spectra were measured for T1D, T1D/E487D, T1D/E487A, and T1D/D94E (Figure 3). The X and Q-band spectra were simulated to obtain the $g$ and A values (figure S3, Supporting Information). These parameters are identical in T1D and the two E487 mutants. This shows that these mutations have no affect on the ground state of the T2 site. T1D/D94E, does however, show some differences relative to T1D, specifically lower values for $\mathrm{g}_{\mathrm{x}}$ and $\mathrm{A}_{\mathrm{z}}$ (figure $\mathrm{S} 3$, Supplementary Material). These results might be expected as residue D94 is located close to the T2 site, with an H-bond through a water molecule to the $\mathrm{T} 2 \mathrm{Cu}$ $\mathrm{OH}^{-}$ligand, while E487 is located on the opposite side of the TNC.

Low-temperature MCD spectra of T1D, T1D/E487D, T1D/E487A, and T1D/D94E are shown in Figure 4. Gaussian fits of the MCD spectra show that 9 transitions between the energies of 5000 and $33000 \mathrm{~cm}^{-1}$ are required (figure $\mathrm{S} 4$, Supporting Information). The four lowest energy transitions have been assigned as the T2 Cu(II) LF transitions: $\mathrm{d}_{x y}, \mathrm{~d}_{z}{ }^{2}, \mathrm{~d}_{x z}$, and $\mathrm{d}_{y z} \rightarrow \mathrm{d}_{x}{ }^{2}-{ }^{2}$, in order of increasing energy. ${ }^{33}$ These transitions are unchanged in the E487 mutants as compared to T1D. This correlates with the EPR data indicating that the structure of the T2 site is unchanged upon mutation at this residue. T1D/D94E in Figure 5D does show a change in the LF of the T2 site, with three of the transitions $\left(\mathrm{d}_{x y}, \mathrm{~d}_{z}{ }^{2}\right.$, and $\left.\mathrm{d}_{y z} \rightarrow \mathrm{d}_{x}{ }^{2}-y^{2}\right)$ increasing in energy while the fourth $\left(\mathrm{d}_{x z}\right)$ shows a decrease in energy (figure S4, Supporting Information). This again reflects the location of D94 in close proximity to, and connected by H-bonds through a water molecule to the $\mathrm{OH}^{-}$ligand on, the $\mathrm{T} 2$.

The remaining 5 transitions in the MCD spectra (Figure 4) are all CT transitions of the $\mathrm{T} 2 \mathrm{Cu}$, $\mathrm{His} \pi \rightarrow \mathrm{Cu}$ in the case of 5 and $7-9$, and $\mathrm{OH}^{-} \rightarrow \mathrm{Cu}$ in the case of band 7.33 The E487 mutations, interestingly, have an effect on the CT region of the MCD spectrum. This is most obvious in bands 5-7 which have changed sign from negative to positive and also shifted to higher energy (Figure 5). Bands 8 and 9 have similar intensity in T1D and the T1D/E487 mutants, but band 8 is slightly lower in energy in both mutants and band 9 has shifted to slightly higher energy. Thus, while the overall structure of the T2 site has been relatively unchanged in the two E487 mutants, the interaction of the ligands with the T2 has been affected. The D94E mutant has resulted in larger changes in the CT region of the MCD spectrum. These are primarily seen in the intensities of bands 5-8. This again reflects a change in the interaction of the two His residues and the $\mathrm{OH}^{-}$ligand with the $\mathrm{T} 2 \mathrm{Cu}$ site.

Overall, the E487 variants have led to stable and intact trinuclear clusters and the structure of the cluster has not been greatly affected. However, the hydroxide bridge at the T3 $\mathrm{Cu}$ site and the interaction of the $\mathrm{T} 2 \mathrm{Cu}$ with its ligands appear to have been impacted as seen in the CT region of the $\mathrm{CD}$ and $\mathrm{MCD}$ spectra, respectively. The D94E mutation, while still loading an intact and stable trinuclear cluster, has had more impact upon the structure of the cluster as seen by the changes in the LF transition energies of the $\mathrm{T} 2$ site and the $\mathrm{T} 3 \mathrm{Cu}$ atom to which it is H-bonded (Figure 1).

\section{4. $\mathrm{pH}$ effect on the resting $\mathrm{T} 2 \mathrm{Cu}$ site}

It has been observed in T1D Fet 3 that there is a $\mathrm{pH}$ effect on the resting $\mathrm{T} 2 \mathrm{Cu}$ site. This is best probed by the appearance of a band in the MCD spectrum at $7700 \mathrm{~cm}^{-1}$ upon going from high to low $\mathrm{pH}$ with a pKa $<5.8$ (Figure 5A indicated by arrow). ${ }^{33,34}$ The LF MCD spectra of T1D/E487D, T1D/E487A, and T1D/D94E at both pD 7.5 and 5.8 are also shown in Figure 5. The $\mathrm{pH}$ dependence of the MCD spectra of the $\mathrm{E} 487$ mutants (figures 5B and 5C) shows that 
they both behave similarly to T1D (Figure 5A) but with a slightly more intense $7700 \mathrm{~cm}^{-1}$ band. The MCD spectrum of the T1DD94E mutant, on the other hand, does not exhibit the new $7700 \mathrm{~cm}^{-1}$ feature at low $\mathrm{pH}$ (Figure 5D). (The LF MCD spectrum of T1DD94A similarly does not exhibit this transition at low $\mathrm{pH} .{ }^{34}$ ) These data argue for a model where D94 is involved in this $\mathrm{pH}$ effect but E487 plays no part. A mechanism can then be developed in which protonation of residue D94 would cause a change in the H-bond network between D94 and the $\mathrm{T} 2 \mathrm{Cu} \mathrm{OH}^{-}$ligand. This would in turn lead to a change in the orientation of the $\mathrm{OH}^{-}$(Figure 6) and shift of the T2 $\mathrm{Cu} \mathrm{d}_{x y}$ orbital leading to the observed $7700 \mathrm{~cm}^{-1}$ transition in MCD. ${ }^{34}$

\section{Spectroscopy of the Peroxide Intermediate}

When the T1D or T1Hg forms of the MCOs are fully reduced and reacted with oxygen they form the peroxide intermediate (PI). ${ }^{32,34}$ In this intermediate two $\mathrm{Cu}$ atoms in the TNC are oxidized and AF coupled and the other $\mathrm{Cu}$ reduced. As a result, $\mathrm{PI}$ has an $\mathrm{S}=0$ ground state and is not accessible by EPR and MCD but its does have unique absorption and $\mathrm{CD}$ features. PI was formed in T1D Fet3 as well as T1D/E487D, T1D/E487A, and T1D/D94E mutants. It is important to note that the reaction of E487A with $\mathrm{O}_{2}$ is in strong contrast to D94A where the reduced TNC does not react with $\mathrm{O}_{2}$. This suggests an important role of charge at the position of residue 94 which will be addressed further in the Discussion section. The absorption and CD spectra of these PI's, shown in Figure 7 (specific transition energies are given in figure S6, Supporting Inormation), while similar, do have quantitative differences. The absorption spectra are all dominated by two intense CT transitions at 340 and $480 \mathrm{~nm}$. These can be further resolved into four bands in the CD spectrum, 6-9, found at similar energies in all variants. These four transitions are peroxide $\pi^{*}{ }_{v}$ and $\pi^{*}{ }_{\sigma}$ to $\mathrm{Cu}$ (II) CT transitions. The presence of four peroxide to $\mathrm{Cu}$ (II) $\mathrm{CT}$ transitions indicates that peroxide must bind to the cluster internally, bridging the two oxidized Cu's. ${ }^{27}$ The fact that these four bands do not significantly change in energy for any of the mutants indicates that peroxide bridges the TNC is a similar fashion in all mutants.

Transitions 1-5 (Figure 7; the CD spectrum of T1D PI from $5000-33,000 \mathrm{~cm}^{-1}$ is shown in figure S5, Supporting Information) have all been assigned as LF transitions of the two oxidized Cu's. ${ }^{27}$ As in the resting TNC, the energies of these LF bands have not changed dramatically in the E487 mutants. The D94E mutant, however, does impact the LF transitions of PI. This is also expected since D94E perturbs the LF in the resting oxidized form and seems to indicate that the geometries of the Cu's have changed slightly in the T1D/D94E PI versus T1D PI.

\section{Decay kinetics of PI}

The kinetics of decay of PI was studied in T1D Fet3 as well as the three mutants addressed here. ${ }^{32,34}$ The decay of PI to the resting oxidized TNC was followed by the disappearance of the intermediate's peroxide to $\mathrm{Cu}(\mathrm{II}) \mathrm{CT}$ transitions at 340 and $480 \mathrm{~nm}$ in the absorption spectrum. This decay follows simple first order kinetics and can be fit to a single exponential expression to extract the rate constant (example shown in Figure 8). ${ }^{32}$ The $\mathrm{pH}$ dependence of this rate of decay has also been measured and can be fit to a protonation equilibrium model $^{32}$ in which the protonatable species is a nearby carboxylate which is shown in T1D to have a pKa of $5.0 \pm 0.2$ (Figure 9 in red). Similar experiments have been performed on all three mutants. In both T1D/E487D and T1D/D94E the rates of PI decay were $\mathrm{pH}$ dependent with pKa's of $6.1 \pm 0.1$ and $5.7 \pm 0.2$ respectively (Figure 9, T1D/E487D in green and T1D/D94E in blue). Importantly, the rate of PI decay in T1D/E487A has no $\mathrm{pH}$ dependence and is slow across the entire range studied (Figure 9 in black).

All three mutants exhibit a decreased rate of decay at both high and low $\mathrm{pH}$ relative to T1D. Interestingly, however, T1D/D94E exhibited approximately a 10-fold rate enhancement at low $\mathrm{pH}$, similar to T1D, while T1D/E487D shows only a 3-fold rate enhancement. These data 
strongly indicate that both residues E487 and D94 play a role in PI decay, as all three mutants have slowed the rate of PI decay. Their specific roles in this process will be addressed in the Discussion.

T1D Fet 3 and T1Hg laccase both have been found to have small inverse kinetic solvent isotope effects (0.89) on the rate of PI decay at low $\mathrm{pH} .{ }^{32,34}$ This inverse KSIE indicates that the proton involved in $\mathrm{O}-\mathrm{O}$ bond cleavage has formed a stronger bond in the transition state than it has in the reactants, in this case PI. ${ }^{43}$ The KSIE's on PI decay were measured in all 3 mutants. In the case of T1D/E487D at $\mathrm{pH} / \mathrm{pD}=5.0$, the KSIE is 2.0 while in T1D/D94E it is 2.3. In T1D/E487A, where $\mathrm{pH}$ was found to have no impact upon the rate of PI decay, the KSIE is 1.0 (table 3). These results indicate that in both T1D/E487D and T1D/D94E, while a proton transfer is still involved in the rate limiting step of PI decay at low $\mathrm{pH}$ it no longer forms a stronger bond at the transition state, in contrast to the reaction in T1D Fet3p and T1Hg laccase. In the T1D/E487A mutant there is no longer a proton transfer involved in the rate determining step of PI decay at low $\mathrm{pH}$.

Overall, despite the mutations, a peroxide intermediate forms in T1D/E487D, T1D/E487A, and T1D/D94E while it did not form in T1D/D94A. The bound peroxide seems to have been perturbed but is still bound in a similar internally bridged fashion in all mutants. The decay of PI, however, has been strongly impacted in these mutants. The T1D/E487A mutant, most significantly, turns off the rate enhancement at low $\mathrm{pH}$ and the KSIE found in T1D (as well as T1Hg Lc). The T1D/D94E and T1D/E487D mutants also impact the decay, changing the KSIE in both from inverse to normal and the degree of rate enhancement at low pH in T1D/E487D.

\section{Discussion}

This study has compared the affects of mutations at two residues, E487 and D94, in the second coordination sphere of the TNC on its electronic structure and oxygen reactivity. The E487D, E487A, and D94E mutations yielded intact TNC's which react with $\mathrm{O}_{2}$. The E487 mutations behaved similarly. The LF's of both the T3 and T2 Cu sites were unchanged relative to T1D. However, small changes were apparent in the hydroxide bridge at the $\mathrm{T} 3 \mathrm{Cu}$ site that are attributed to the H-bond network that links E487 to this hydroxide bridge (Figure 1). The D94E mutation had much more impact on the structure of the TNC. Fairly large LF changes are apparent in both $\mathrm{T} 2$ and $\mathrm{T} 3$ centers that can be attributed to perturbations of the H-bond network that connects D94 to the $\mathrm{OH}^{-}$ligand on the $\mathrm{T} 2$ and the $\mathrm{H}$-bond to residue $\mathrm{H} 418$ which coordinates to one of the T3 Cu's (Figure 1). In addition, comparison of the $\mathrm{pH}$ dependence of the MCD spectra of these mutants has made clear that residue D94 is responsible for the $\mathrm{pH}$ effect on the resting $\mathrm{T} 2 \mathrm{Cu}$ site, while residue $\mathrm{E} 487$ is not involved.

From the data on all the mutants addressed in this study, roles for both E487 and D94 can be assigned in the $\mathrm{O}-\mathrm{O}$ bond cleavage process. An additional set of data for developing a mechanism is the ${ }^{18} \mathrm{O}$ kinetic isotope effect on PI decay $(1.11 \pm 0.05)$ which has shown that the $\mathrm{O}-\mathrm{O}$ bond must be almost cleaved at the transition state. ${ }^{32} \mathrm{It}$ is known that the product of PI decay is NI, which has both oxygen atoms from reduced $\mathrm{O}_{2}$ bound to the TNC as a $\mu_{3}$-oxo and a $\mu_{2}$-hydroxo bridge, the latter at the $\mathrm{T} 3 \mathrm{Cu}$ 's. ${ }^{43}$ This means that a proton must be transferred to oxygen near the $\mathrm{T} 3 \mathrm{Cu}$ atoms at some point in the $\mathrm{O}-\mathrm{O}$ bond cleavage process. The location of E487 near the T3 site and the affects of its mutation on the decay of PI (Figure 9 and table 3) support its role in the donation of this proton. Using the Westheimer model, ${ }^{44}$ (S7, Supporting Information) transfer of a proton from this carboxylate (O-H bond frequency of $\left.3000 \mathrm{~cm}^{-1}\right)^{45}$ to the $\mu_{2}$-hydroxo bridge $\left(\mathrm{OH} \text { bond frequency of } 3600 \mathrm{~cm}^{-1}\right)^{46}$ through the $\mathrm{H}$-bond network yields the observed inverse KSIE when the O-H bond is mostly formed at the transition state. This model is supported by the results of the E487A mutation that removes a protonatable species from this position and eliminates the $\mathrm{pH}$ dependent rate enhancement and 
the inverse isotope effect of PI decay (table 3). While the E487D mutation does not eliminate the $\mathrm{pH}$ effect and KSIE, it lowers the degree of proton dependent rate enhancement in PI decay and changes the KSIE from inverse to normal (table 3). This KSIE of 2.0 supports a transition state in which the proton is now farther away from its final product position, (S7, Supporting Information) consistent with the shorter carboxylate side chain in Asp relative to the Glu in WT. With respect to the decrease in rate of PI decay in E487D and E487A relative to wild type at high $\mathrm{pH}$, even when $\mathrm{E} 487$ is deprotonated it is still capable of H-bonding to a water molecule which would in turn $\mathrm{H}$-bond to the peroxide in PI. This H-bond network would increase the electron affinity of the peroxide and assist in the reductive cleavage of the $\mathrm{O}-\mathrm{O}$ bond. This $\mathrm{H}$ bond pathway would be disrupted the E487 mutants.

D94 also plays a role in the decay of PI, as the T1D/D94E mutant exhibits a decay of PI which is still $\mathrm{pH}$ dependent but slower than T1D across the entire $\mathrm{pH}$ range. In assigning a role to D94 it is important to emphasize that D94A and D94N do not react with $\mathrm{O}_{2}$ whereas WT and D94E, as well as E487D and E487A, do react to form PI. ${ }^{34}$ Also, computational studies have shown that a negative charge at the $\mathrm{D} 94$ position is required for the $\mathrm{O}_{2}$ reaction. ${ }^{47}$ Thus, D94 must be deprotonated, providing a negative charge, for the TNC to react with $\mathrm{O}_{2}$. Consequently, in the decay of PI, this sets up a pathway through which D94 could assist in removing a proton from the $\mathrm{H}_{2} \mathrm{O}$ ligand on the $\mathrm{T} 2 \mathrm{Cu}$. This conversion of the water to hydroxide would lower the redox potential of the $\mathrm{T} 2$ and increase the driving force for electron transfer to peroxide assisting in O-O bond cleavage. As E487 can only donate a proton at low pH, the KSIE of 1.0 at high $\mathrm{pH}$ is a direct probe of the $\mathrm{T} 2$ water to $\mathrm{D} 94$ proton transfer process and indicates that the proton has been transferred to D94 at the transition state. In the D94E mutant, based upon the elimination of the $\mathrm{T} 2 \mathrm{pH}$ effect in resting, the H-bond network is disrupted and the T2 $\mathrm{H}_{2} \mathrm{O}$ ligand would no longer be able to transfer its proton. This would slow electron transfer in O-O bond cleavage regardless of $\mathrm{pH}$, as observed in the rate of PI decay in the D94E mutant. As the extent of electron transfer to peroxide is decreased, proton transfer by E487 would also be shifted along the reaction coordinate relative to the transition state. This would provide a possible explanation for the normal isotope effect of 2.3 observed in D94E.

Based on the effects of residues E487 and D94 and the kinetic isotope effects, a molecular mechanism for cleavage of the $\mathrm{O}-\mathrm{O}$ bond can be developed. At high pH, E487 is deprotonated and does not play a role in proton transfer during O-O cleavage. D94 will accept a proton from the T2 water ligand, and as the transition state occurs late in O-O cleavage it would also be late in this proton transfer leading to the KSIE of 1.0 at high pH. At low pH E487 transfers its proton leading to an almost completely formed $\mathrm{O}-\mathrm{H}$ bond at the transition state, resulting in the inverse isotope effect of 0.89 . Therefore, at low $\mathrm{pH}$ the TS between PI and NI has a long $\mathrm{O}-\mathrm{O}$ bond and a short $\mathrm{O}-\mathrm{H}$ bond. For this to be the case, the proton transfer from $\mathrm{E} 487$ must begin early with respect to $\mathrm{O}-\mathrm{O}$ bond cleavage. This proton transfer would stabilize the peroxide $\sigma^{*}$ orbitial, polarizing the peroxide and making it easier to reductively cleave its bond as is reflected by the increase in rate at low $\mathrm{pH} .{ }^{48}$ The net effect of this mechanism is a proton flow from E487 to peroxide and from the $\mathrm{H}_{2} \mathrm{O}$ bound to the T2 $\mathrm{Cu}$ to D94 as seen in Figure 10.49

This study of mutants at residues E487, near the T3 site, and D94, near the T2 site, has helped define the role of H-bonding in the structure of the TNC in the MCO's and the role of protons in the reductive cleavage of the O-O bond. The D94E mutation led to relatively large changes in the structure of the TNC and confirmed that D94 is the residue involved in the pH effect on the resting enzyme through a $\mathrm{H}$-bond network to the $\mathrm{OH}^{-}$ligand on the $\mathrm{T} 2 \mathrm{Cu}$. Furthermore, the residue provides a negative charge that is necessary for the reaction of the TNC with $\mathrm{O}_{2}$ and then assists in the deprotonation of the T2 Cu water ligand during PI decay. The E487 mutants led to smaller structural perturbations compared to D94E but this residue is the protonatable species responsible for acceleration of PI decay at low $\mathrm{pH}$ and the inverse KSIE. 
E487 and D94 act together to create a flow of protons from the T3 side of the TNC to the T2 side to drive the reductive cleavage of the O-O bond. Given the structural conservation in the primary through tertiary levels in MCO's from fungi to plants, including E487 and D94 equivalents, the mechanism of proton assisted $\mathrm{O}-\mathrm{O}$ bond cleavage at the TNC is likely conserved as well. Although the domain and tertiary structure of human ceruloplasmin differs from these lower eukaryotic MCO's ${ }^{11}$, it retains these two protic groups, E1032 and D995 respectively. Thus, the mechanism outlined here applies to all of the MCO family of enzymes.

\section{Supplementary Material}

Refer to Web version on PubMed Central for supplementary material.

\section{Acknowledgements}

We thank Dr. Jungjoo Yoon for helpful discussion about O-O bond cleavage in the MCO's and Dr. Abishek Dey for discussions about kinetics and isotope effects. This research was supported by NIH Grants DK31450 (to E.I.S.) and DK53820 (to D.J.K.). A.J.A is a John Stauffer Stanford Graduate Fellow.

\section{References}

1. Solomon EI, Sundaram UM, Machonkin TE. Chem Rev 1996;96:2563-2605. [PubMed: 11848837]

2. Nitta K, Kataoka K, Sakurai T. J Inorg Biochem 2002;91:125-131. [PubMed: 12121769]

3. Jonsson L, Sjostrom K, Haggstrom I, Nyman PO. Biochim Biophys Acta 1995;1251:210-215. [PubMed: 7669813]

4. Messerschmidt A, Rossi A, Ladenstein R, Huber R, Bolognesi M, Guiseppina G, Marchesini A, Petruzzelli R, Finazzi-Agro A. J Mol Biol 1989;206:513-529. [PubMed: 2716059]

5. Bento I, Martins LO, Lopes GG, Carrondo MA, Lindley PF. Dalton Trans 2005;21:3507-3513. [PubMed: 16234932]

6. Smith AW, Camara-Artigas A, Wang MT, Allen JP, Francisco WA. Biochemistry 2006;45:43784387. [PubMed: 16584173]

7. Quintanar L, Gebhard M, Wang TP, Kosman DJ, Solomon EI. J Am Chem Soc 2004;126:6579-6589. [PubMed: 15161286]

8. Stoj C, Augustine AJ, Zeigler L, Solomon EI, Kosman DJ. Biochemistry 2006;45:12741-12749. [PubMed: 17042492]

9. Stoj CS, Augustine AJ, Solomon EI, Kosman DJ. J Biol Chem 2007;282:7862-7868. [PubMed: 17220296]

10. de Silva D, Askwith CC, Eide D, Kaplan J. J Biol Chem 1995;270:1098-1101. [PubMed: 7836366]

11. Zaitseva I, Zaitsev V, Card G, Moshkov K, Bax B, Ralph A, Lindley P. J Biol Inorg Chem 1996;1:1523.

12. Roberts S, Weichsel A, Grass G, Thakali K, Hazzard J, Tollin G, Rensing C, Montfort W. Proc Natl Acad Sci USA 2002;99:2766-2771. [PubMed: 11867755]

13. Francis CA, Casciotti KL, Tebo BM. Arch Microbiol 2002;178:450-456. [PubMed: 12420165]

14. Allendorf MD, Spira DJ, Solomon EI. Proc Natl Acad Sci USA 1985;82:3063-3067. [PubMed: 2987909]

15. Spira-Solomon DJ, Allendorf MD, Solomon EI. J Am Chem Soc 1986;108:5318-5328.

16. Messerschmidt A, Ladenstein R, Huber R, Bolognesi M, Avigliano L, Petruzzelli R, Rossi A, FinazziAgro A. J Mol Biol 1992;224:179-205. [PubMed: 1548698]

17. Taylor AB, Stoj CS, Ziegler L, Kosman DJ, Hart PJ. Proc Natl Acad Sci USA 2005;102:15459_ 15464. [PubMed: 16230618]

18. Cole JL, Tan GO, Yang EK, Hodgson KO, Solomon EI. J Am Chem Soc 1990;112:2243-2249.

19. Solomon EI, Chen P, Metz M, Lee SK, Palmer AE. Angew Chem, Int Ed 2001;40:4570-4590.

20. Andréasson LE, Reinhammar B. Biochim Biophys Acta 1976;445:579-597. [PubMed: 9990] 
21. Andréasson LE, Brändén R, Reinhammar B. Biochim Biophys Acta 1976;438:370-379. [PubMed: 182231]

22. Lee SK, George SD, Antholine WE, Hedman B, Hodgson KO, Solomon EI. J Am Chem Soc 2002;124:6180-6193. [PubMed: 12022853]

23. Yoon J, Mirica LM, Stack TDP, Solomon EI. J Am Chem Soc 2005;127:13680-13693. [PubMed: 16190734]

24. Yoon J, Liboiron BD, Sarangi R, Hodgson KO, Hedman B, Solomon EI. Proc Natl Acad Sci USA. 2007in press

25. Cole JL, Clark PA, Solomon EI. J Am Chem Soc 1990;112:9534-9548.

26. Blackburn NJ, Ralle M, Hassett R, Kosman DJ. Biochemistry 2000;39:2316-2324. [PubMed: 10694398]

27. Palmer AE, Quintanar L, Severance S, Wang TP, Kosman DJ, Solomon EI. Biochemistry 2002;41:6438-6448. [PubMed: 12009907]

28. Shin W, Sundaram UM, Cole JL, Zhang HH, Hedman B, Hodgson KO, Solomon EI. J Am Chem Soc 1996;118:3202-3215.

29. Cole JL, Ballou DP, Solomon EI. J Am Chem Soc 1991;113:8544-8546.

30. Sundaram UM, Zhang HH, Hedman B, Hodgson KO, Solomon EI. J Am Chem Soc 1997;119:1252512540.

31. Rulíšek L, Solomon EI, Ryde U. Inorg Chem 2005;44:5612-5628. [PubMed: 16060610]

32. Palmer AE, Lee SK, Solomon EI. J Am Chem Soc 2001;123:6591-6599. [PubMed: 11439045]

33. Quintanar L, Yoon J, Aznar C, Palmer AE, Andersson K, Britt D, Solomon EI. J Am Chem Soc 2005;127:13832-13845. [PubMed: 16201804]

34. Quintanar L, Stoj C, Wang TP, Kosman DJ, Solomon EI. Biochemistry 2005;44:6081-6091. [PubMed: 15835897]

35. Hassett RF, Yuan DS, Kosman DJ. J Biol Chem 1998;273:23274-23282. [PubMed: 9722559]

36. Askwith C, Eide D, VanHo A, Bernard PS, Li L, Davis-Kaplan S, Sipe DM, Kaplan J. Cell 1994;76:403-410. [PubMed: 8293473]

37. Bradford MM. Anal Biochem 1976;72:248-254. [PubMed: 942051]

38. Felsenfeld G. Arch Biochem Biophys 1960;87:247-251. [PubMed: 13822131]

39. Carithers RP, Palmer G. J Biol Chem 1981;256:7967-7976. [PubMed: 6267032]

40. Machonkin TE, Quintanar L, Palmer AE, Hassett R, Severance S, Kosman DJ, Solomon EI. J Am Chem Soc 2001;123:5507-5517. [PubMed: 11389633]

41. Kosman DJ, Hassett R, Yuan DS, McCracken J. J Am Chem Soc 1998;120:4037-4038.

42. In the spectra shown in figure $3, \varepsilon 3000 \mathrm{M}^{-1} \mathrm{~cm}^{-1}$ for the $330 \mathrm{~nm}$ band because the spectrum of the reduced protein has been subtracted to eliminate the contribution of the protein $280 \mathrm{~nm}$ band. In the presence of the $280 \mathrm{~nm}$ band the $\varepsilon 5000 \mathrm{M}^{-1} \mathrm{~cm}^{-1}$ for the $330 \mathrm{~nm}$ band.

43. Klinman JP. Adv Enzymol 1978;46:415-494. [PubMed: 345770]

44. Westheimer FH. Chem Rev 1961;61:265-273.

45. Morrison, RT.; Boyd, RN. Organic Chemistry. 6. Allyn and Bacon; Newton, MA: 1987. p. 849-851.

46. Kitajima N, Fujisawa K, Fujimoto C, Morooka Y, Hashimoto S, Kitagawa T, Toriumi K, Tatsumi K, Nakamura A. J Am Chem Soc 1992;114:1277-1291.

47. Yoon J, Solomon EI. J Am Chem Soc. Submitted

48. Root DE, Mahroof-Tahir M, Karlin KD, Solomon EI. Inorg Chem 1998;37:4838-4848. [PubMed: 11670647]

49. The starting structure in this mechanism is $\mathrm{PI}+\mathrm{e}^{-}$where in the holo-enzyme an electron from the reduced $\mathrm{T} 1 \mathrm{Cu}$ in $\mathrm{PI}$ has been transferred to the TNC and the $\mathrm{O}-\mathrm{O}$ bond is ready to undergo a two electron reductive cleavage. 


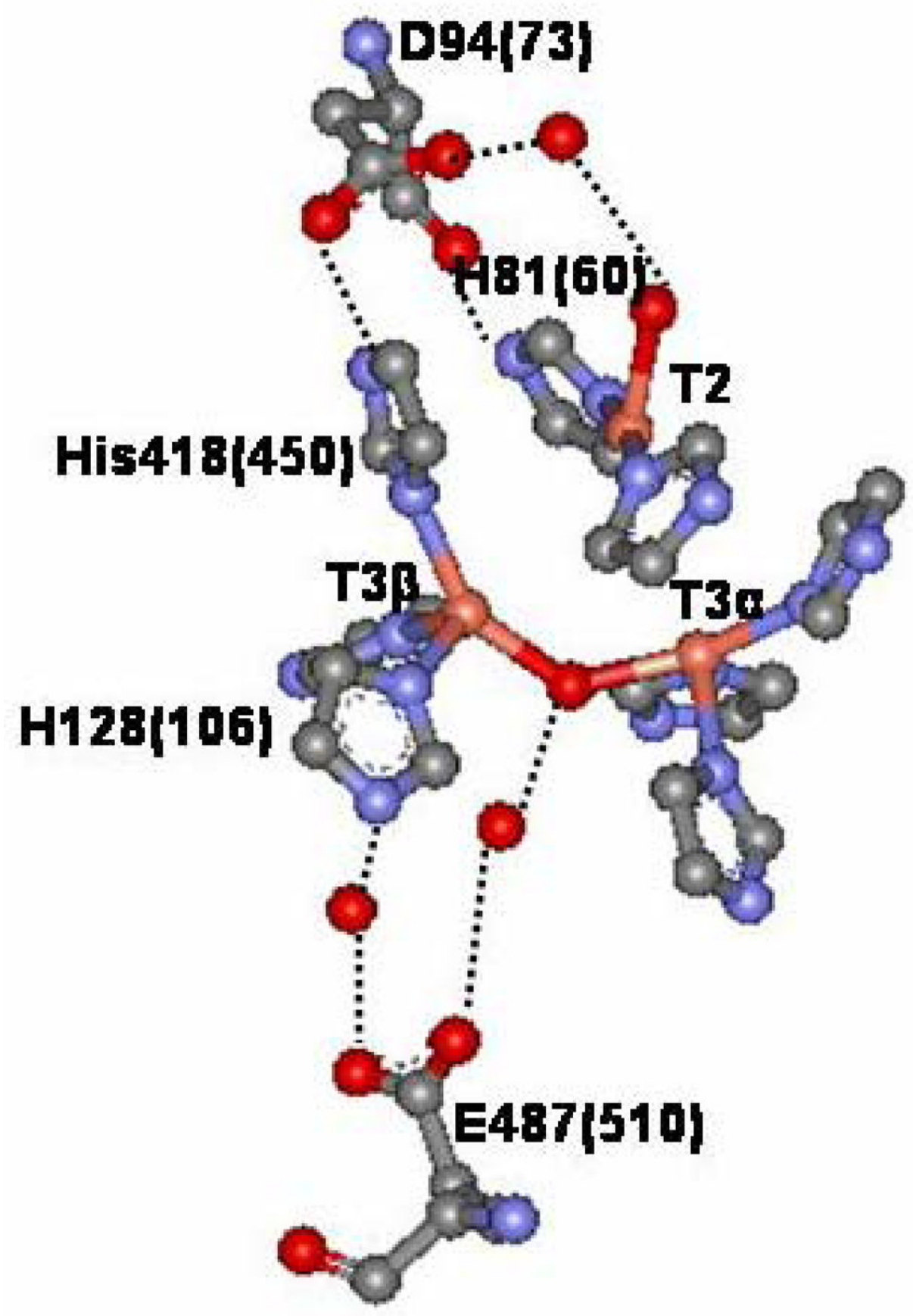

Figure 1. Structure of the TNC

(Structure shown and amino acid numbers in parentheses are from ascorbate oxidase ${ }^{16}$ in which amino acid positions have been shown to be very similar to those in the structure of Fet3p ${ }^{17}$.) 

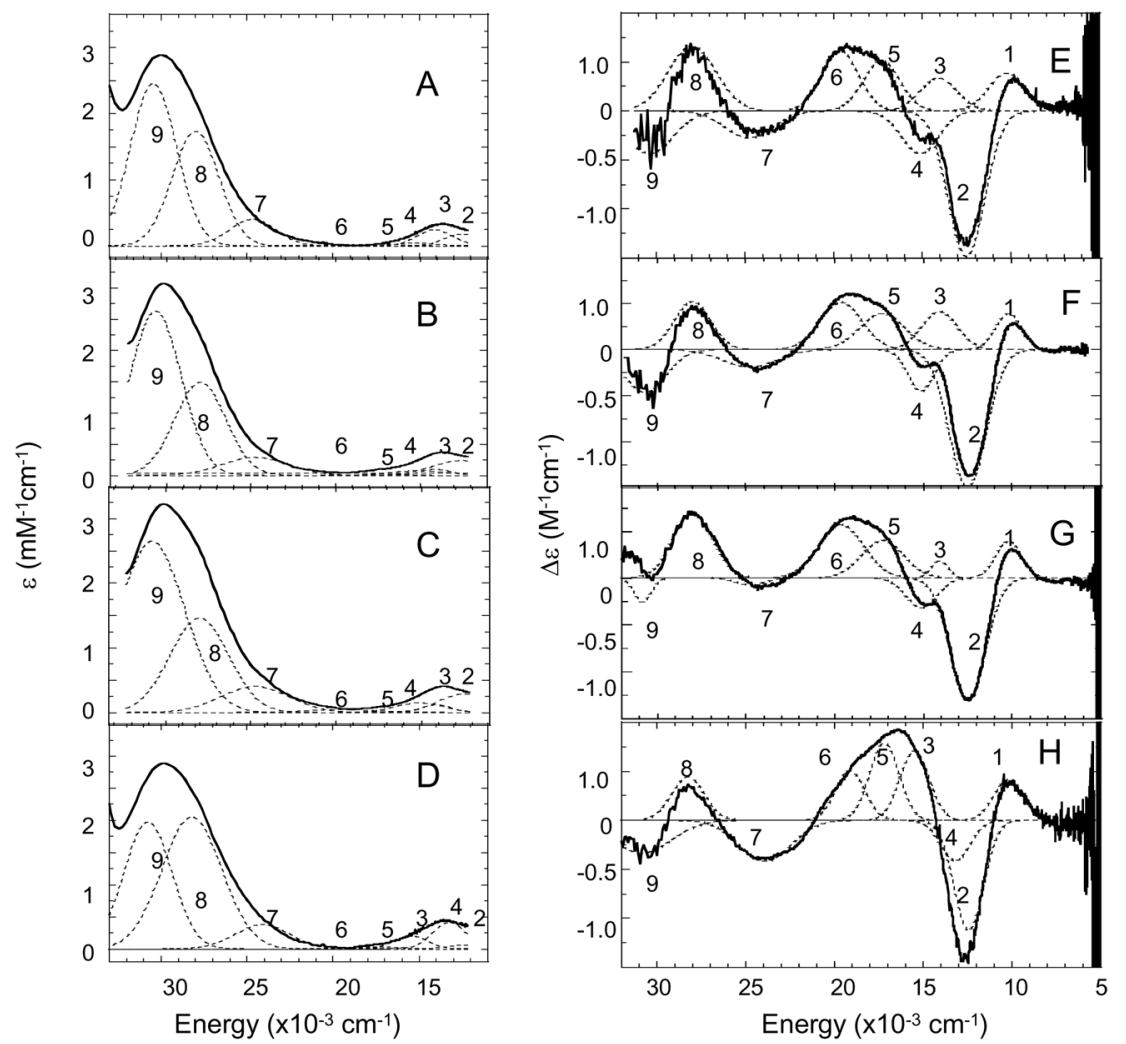

Figure 2.

Room temperature difference (oxidized - reduced to remove contribution of protein $280 \mathrm{~nm}$ band) absorption spectra of T1D (A), T1DE487D (B), T1DE487A (C), and T1DD94E (D). CD spectra of T1D (E), T1DE487D (F), T1DE487A (G), and T1DD94E (H). Individual Gaussian bands are shown with dotted lines. 

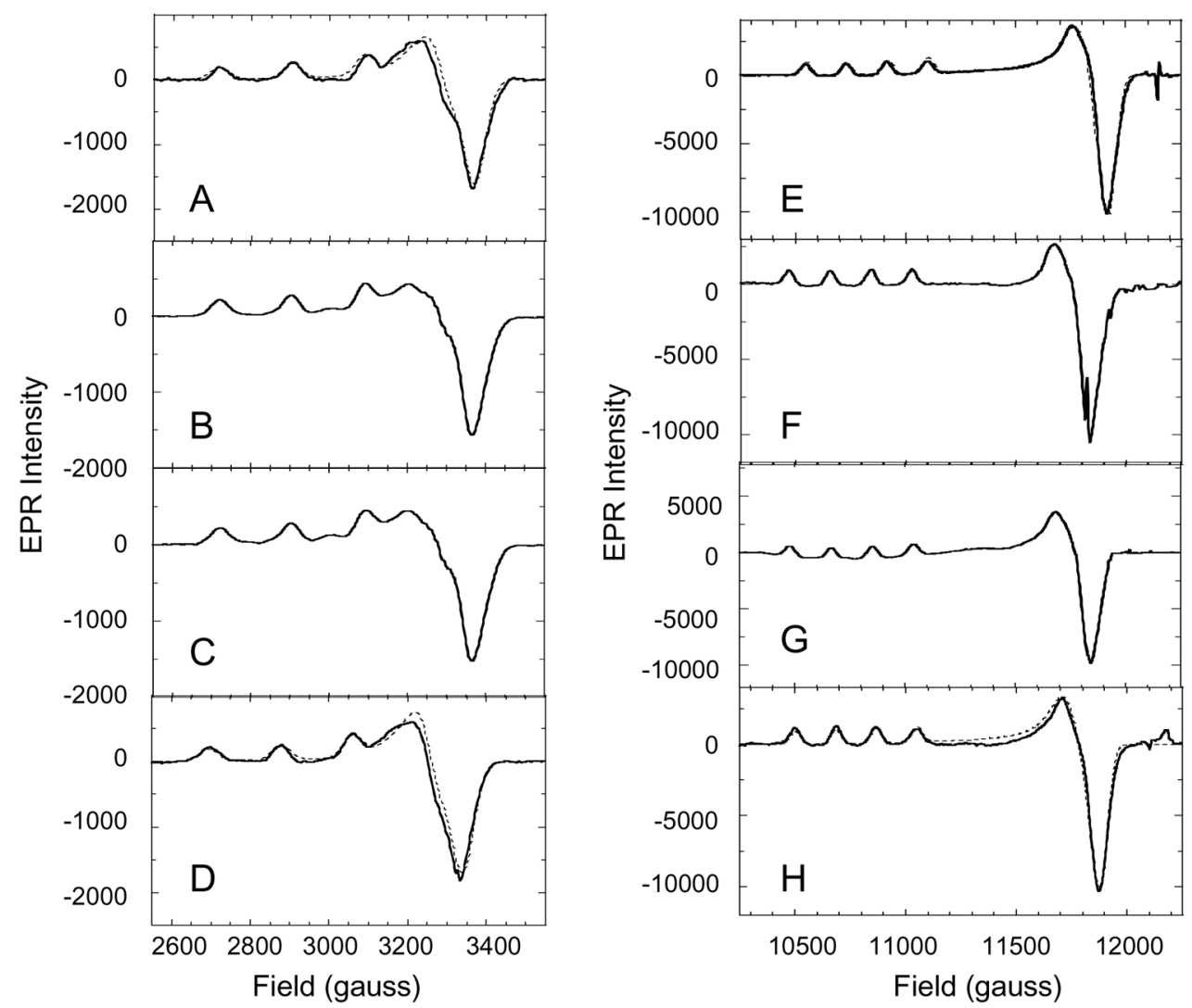

Figure 3.

X-Band EPR spectra of T1D (A), T1DE487D (B), T1DE487A (C), and T1DD94E (D). Q-band EPR spectra of T1D (E), T1DE487D (F), T1DE487A (G), and T1DD94E (H). Simulations are shown in dotted lines. All spectra were obtained at $77 \mathrm{~K}$ 


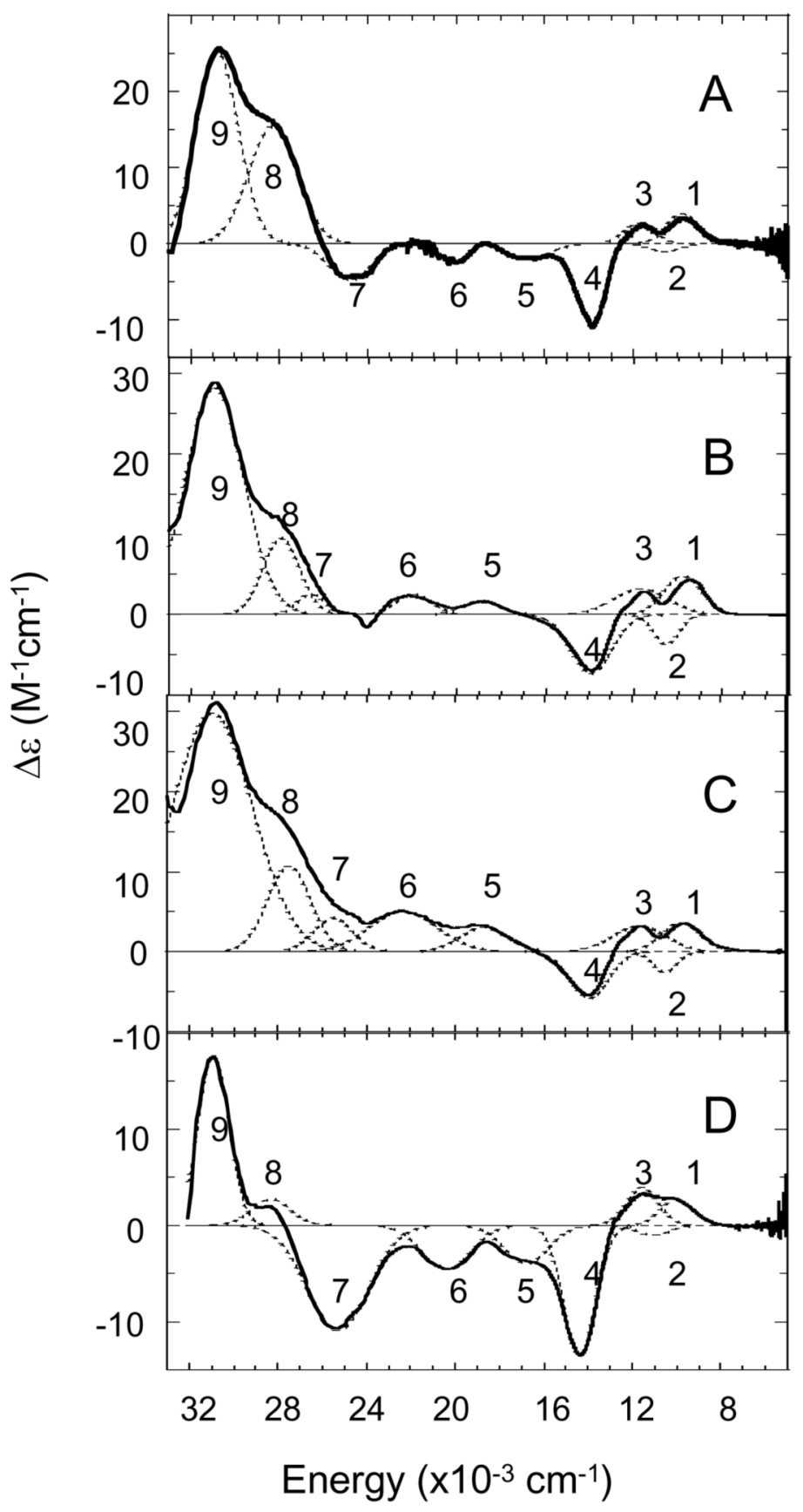

Figure 4.

MCD spectra obtained at 7T and $5 \mathrm{~K}$ of T1D (A), T1DE487D (B), T1DE487A (C), and T1DD94E (D). Individual Gaussian bands are shown with dotted lines. 


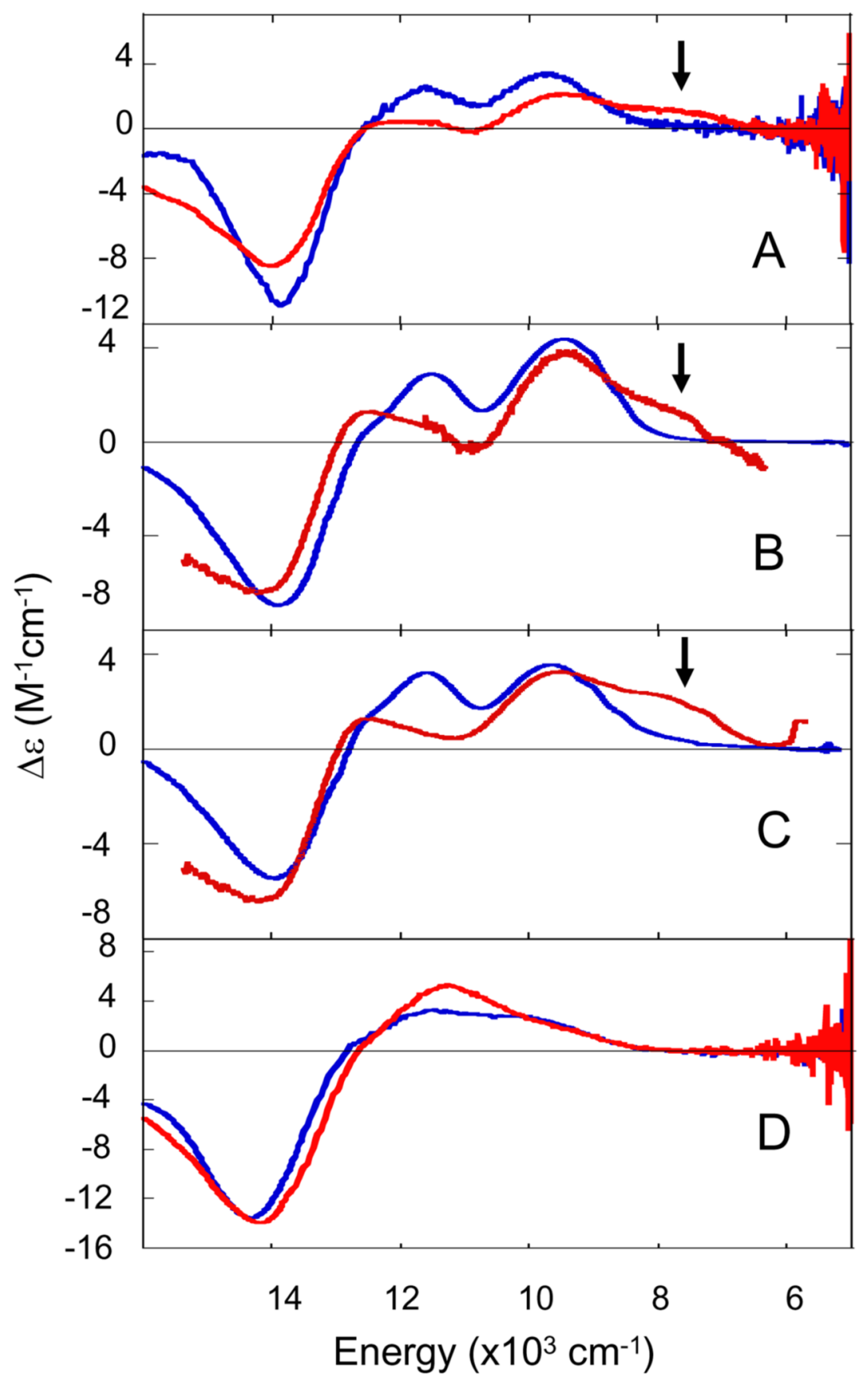

Figure 5.

LF MCD spectra obtained at 7T and $5 \mathrm{~K}$ of T1D (A), T1DE487D (B), T1DE487A (C), and T1DD94E (D). In blue is $\mathrm{pD}=7.5$ and in red $\mathrm{pD} 5.8$. 

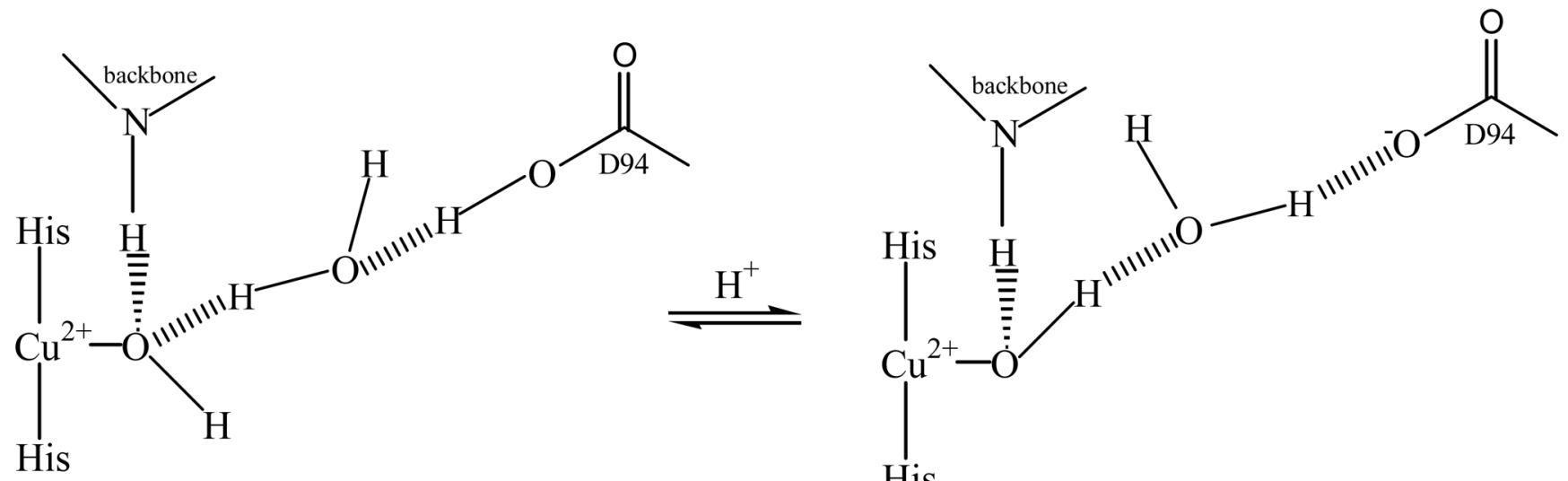

Figure 6.

H-bond network between D94 and resting T2 Cu site 

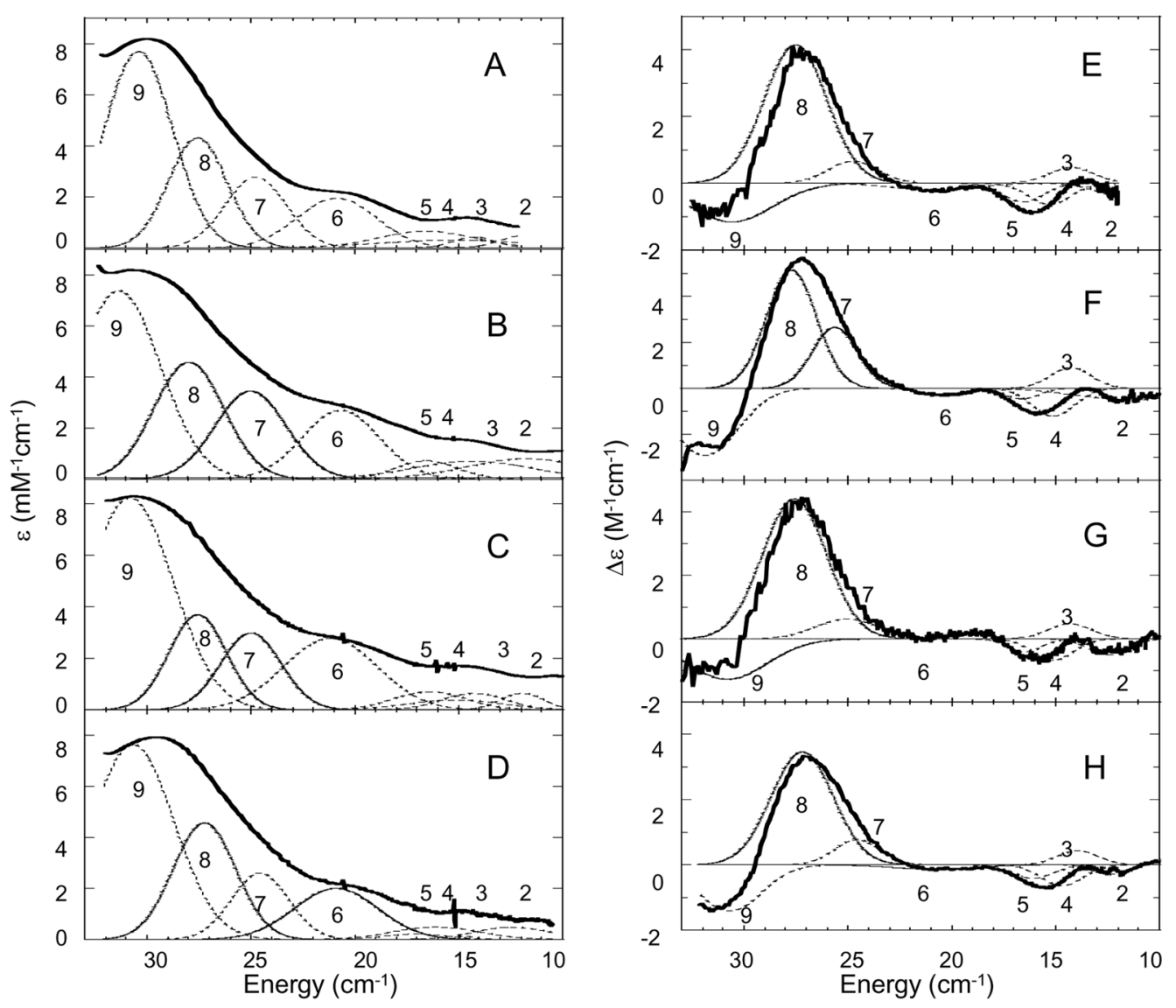

Figure 7.

Room temperature absorption spectra of PI in T1D (A), T1DE487D (B), T1DE487A (C), and T1DD94E (D). CD spectra of PI in T1D (E), T1DE487D (F), T1DE487A (G), and T1DD94E $(\mathrm{H})$. Individual Gaussian bands are shown with dotted lines. 


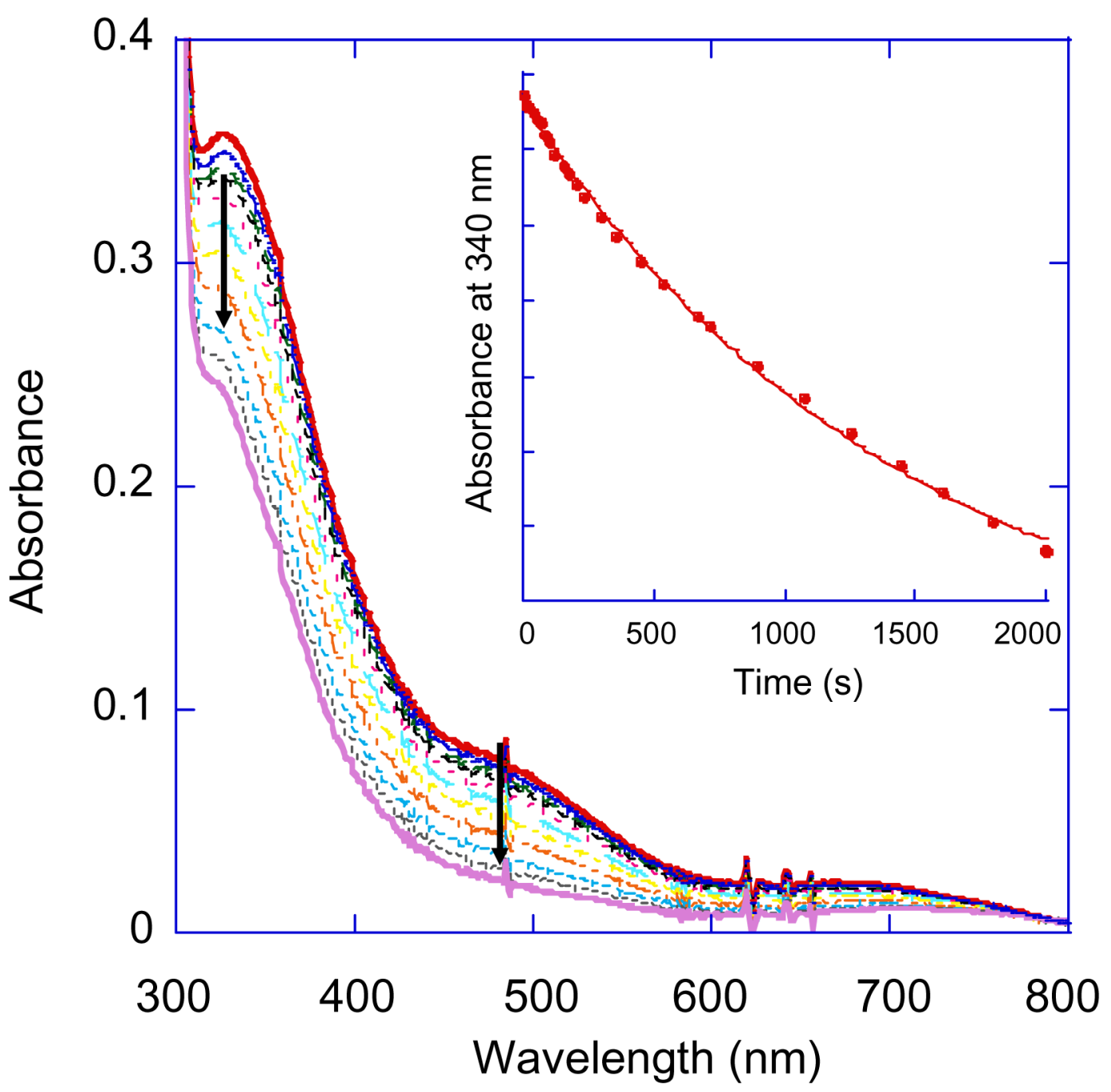

Figure 8.

Decay of PI followed by absorption in T1DE487A at $\mathrm{pH}=5.0$. The inset shown traces the absorbance at $340 \mathrm{~nm}$ over time and was fit, along with similar trace at $480 \mathrm{~nm}$, to obtain the rate of decay. 


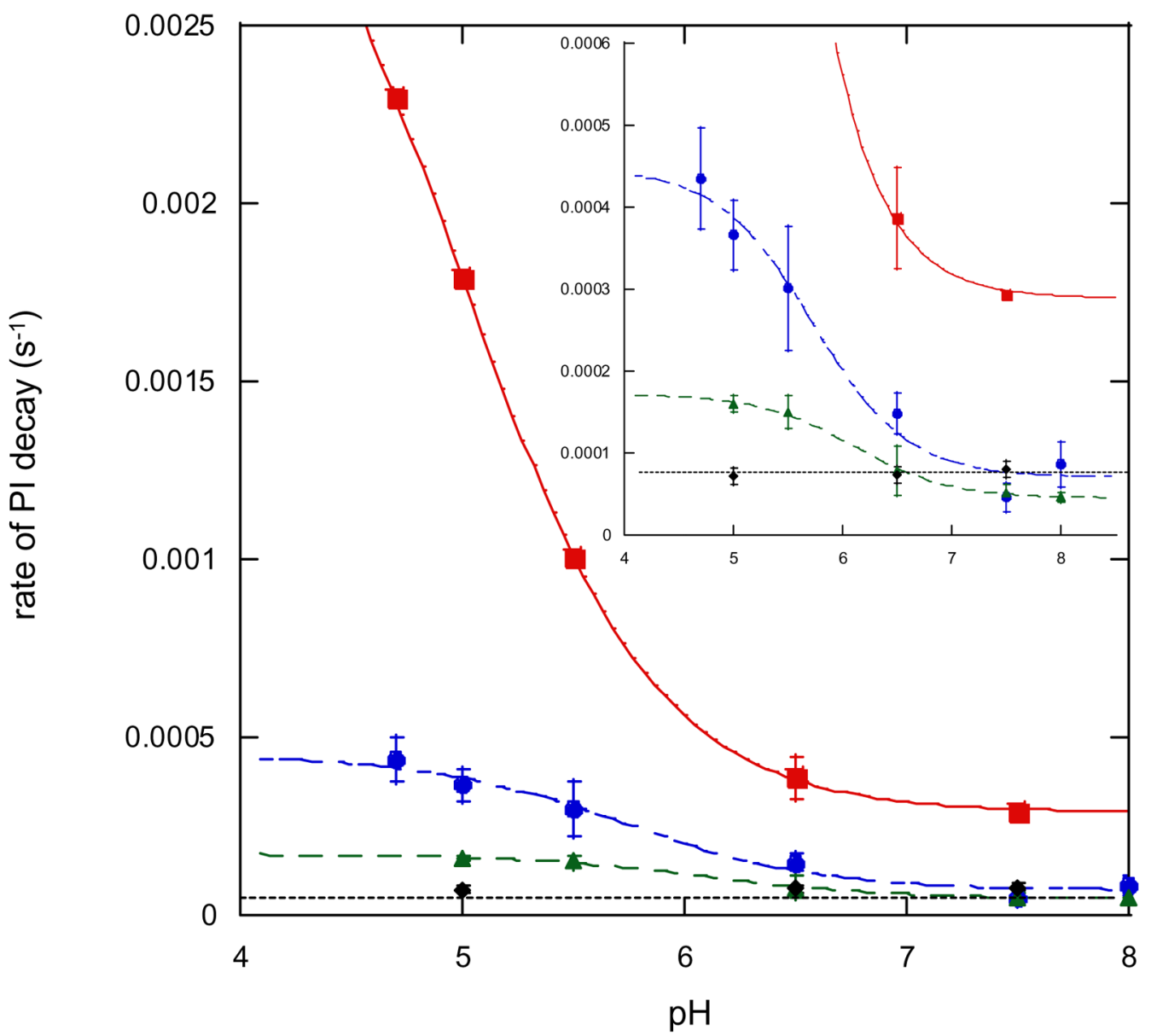

Figure 9.

Rate of decay of PI as a function of $\mathrm{pH}$. T1D is shown in $\boldsymbol{\bullet}$, T1DE487D in $\boldsymbol{\Delta}$, T1DE4987A in $>$, and T1DD94E in $\bullet$. 

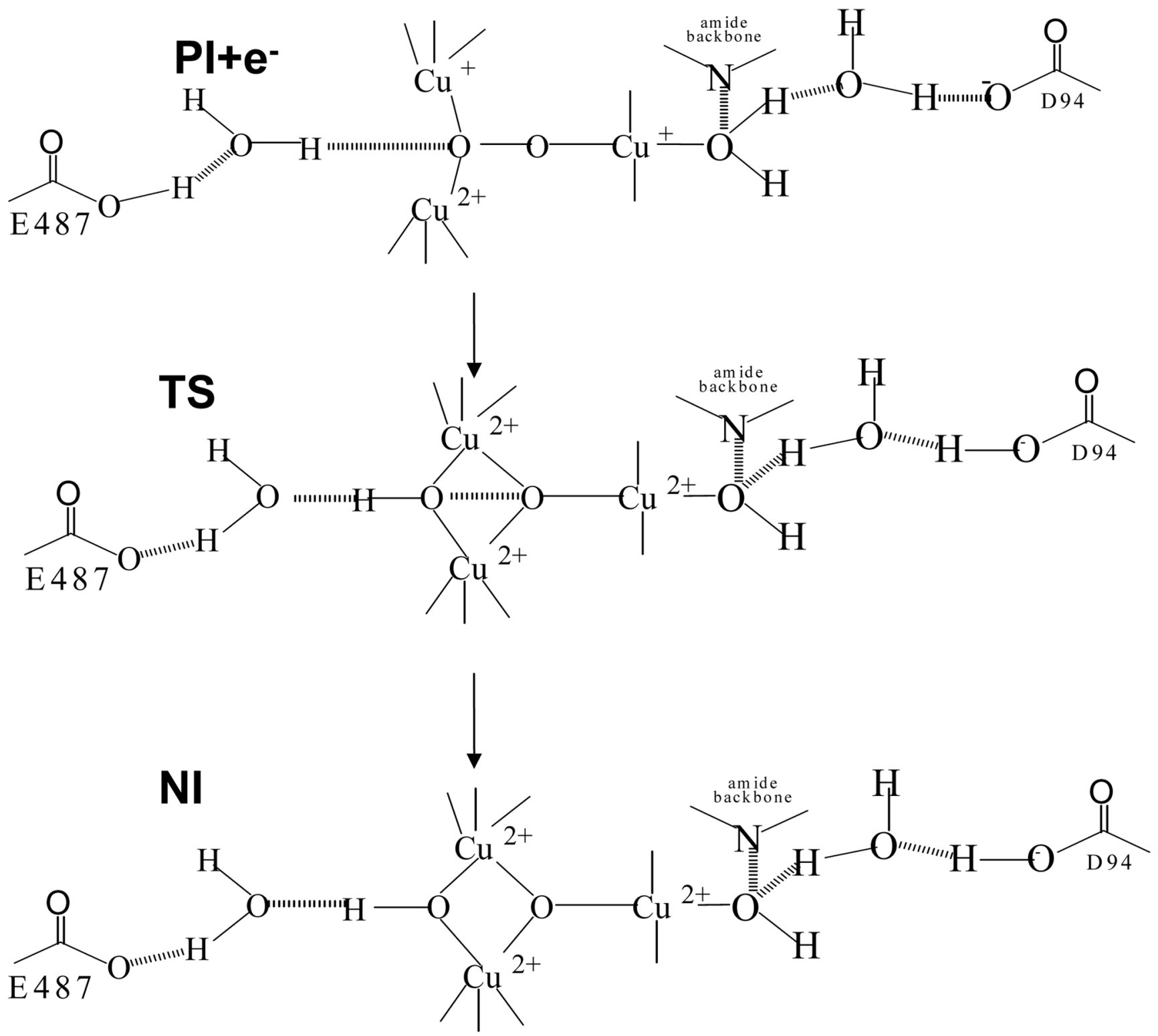

Figure 10.

Schematic showing cleavage of the $\mathrm{O}-\mathrm{O}$ bond and the TS between $\mathrm{PI}+\mathrm{e}^{-}$(PI plus an electron from the $\mathrm{T} 1 \mathrm{Cu}$ ) and $\mathrm{NI}$ 
Table 1

$\mathrm{Cu}$ content and spin quantitation of Fet $3 p$ mutants

\begin{tabular}{|c|c|c|}
\hline & Copper Content (Cu/protein) & EPR spin quantitation (spin/protein) \\
\hline WT & $4.2 \pm 0.3$ & $1.8 \pm 0.3$ \\
\hline E487D & $3.9 \pm 0.4$ & $1.6 \pm 0.4$ \\
\hline E487A & $3.9 \pm 0.4$ & $1.2 \pm 0.4$ \\
\hline D94E & $4.3 \pm 0.2$ & $1.8 \pm 0.2$ \\
\hline T1D & $3.2 \pm 0.2$ & $0.8 \pm 0.3$ \\
\hline T1D/E487D & $2.8 \pm 0.3$ & $0.7 \pm 0.2$ \\
\hline T1D/E487A & $2.7 \pm 0.3$ & $0.7 \pm 0.2$ \\
\hline T1D/D94E & $3.2 \pm 0.3$ & $0.7 \pm 0.2$ \\
\hline
\end{tabular}




\section{Table 2}

Turnover rates for holo enzymes

\begin{tabular}{|r|r|r|}
\hline Fet3p species & $\boldsymbol{K}_{\mathbf{M}}(\boldsymbol{\mu M})$ & $\boldsymbol{V}_{\max }\left(\mathbf{m i n}^{-1}\right)$ \\
\hline WT & $4.5 \pm 0.9$ & $19.3 \pm 0.8$ \\
\hline D94E & $2.3 \pm 0.5$ & $14.9 \pm 0.4$ \\
\hline I & $9.8 \pm 2.5$ & $22.4 . \pm 1.8$ \\
\hline E487D & $11.4 \pm 2.3$ & $11.7 \pm 0.8$ \\
\hline E487A & \multicolumn{2}{|c}{}
\end{tabular}


Table 3

Summary of the affect of various mutations upon the $\mathrm{pH}$ effect in PI decay and the $\mathrm{pH}$ effect on the resting $\mathrm{T} 2 \mathrm{Cu}$

\begin{tabular}{|l|l|l|l|l|}
\hline & T1D & T1DE487D & T1DE487A & T1DD94E \\
\hline Rate of PI decav $\mathrm{pH}=5.0$ & $1.8 \times 10-3 \mathrm{~s}-1$ & $1.6 \pm 0.1 \times 10-4 \mathrm{~s}-1$ & $7.2 \pm 0.5 \times 10-5 \mathrm{~s}-1$ & $3.7 \pm 0.4 \times 10-4 \mathrm{~s}-1$ \\
\hline Rate of PI decay $\mathrm{pH}=7.5$ & $2.9 \times 10-4 \mathrm{~s}-1$ & $5.2 \pm 0.9 \times 10-5 \mathrm{~s}-1$ & $8 \pm 1 \times 10-5 \mathrm{~s}-1$ & $4 \pm 1 \times 10-5 \mathrm{~s}-1$ \\
\hline Rate enhancement & $6.2 \mathrm{x}$ & $3.1 \mathrm{x}$ & $1 \mathrm{x}$ & $8.0 \mathrm{x}$ \\
\hline KSIE @ low $\mathrm{pH}$ & 0.89 & 2.0 & $\sim 1$ & 2.3 \\
\hline $\mathrm{pH}$ effect on resting T2 Cu & ves & ves & ves & No \\
\hline
\end{tabular}

The KSIE at high $\mathrm{pH}$ (measured at $\mathrm{pH}=7.5$ ) is 1.0 for T1D and all mutants 